\title{
Colour vision in patients with chronic simple glaucoma and ocular hypertension
}

\author{
D. POINOOSAWMY, S. NAGASUBRAMANIAN, AND J. GLOSTER \\ From the Glaucoma Unit, Institute of Ophthalmology, and \\ Moorfields Eye Hospital, London
}

SUMMARY Normal subjects and patients with chronic simple glaucoma and ocular hypertension were examined with the Farnsworth-Munsell 100 hue test. Two groups of glaucoma patients were studied, one group having field defects in both eyes and the other being 'unilateral' in the sense that one eye had a full visual field. The stage of the disease was assessed by the amount of field loss or by the amount of optic disc damage as expressed by the vertical cup:disc ratio. Hue discrimination in eyes with glaucomatous field defects was worse than in eyes of normal subjects, but there was no clear indication of one range of colours being more affected than another. In glaucoma patients with field defects in both eyes the difference in error scores between the 2 eyes was greater than in normal subjects. There was a significant correlation between the degree of impairment of hue discrimination, expressed as the error score, and the amount of glaucomatous field loss. There was also a significant correlation between error score and the amount of glaucomatous damage to the optic disc, expressed by the vertical cup:disc ratio. Findings in a group of patients with ocular hypertension suggested that some of these were cases of incipient glaucoma.

Defective colour vision has been established as part of the impairment of visual function in eyes affected by chronic simple glaucoma. ${ }^{1-5}$ The main purpose of the investigation reported in this paper was to study the relationship of the degree of loss of hue discrimination to the stage of glaucoma, the latter being assessed not only in terms of visual field loss, but also in relation to optic disc damage expressed quantitatively as the vertical cup: disc ratio. Hue discrimination tests were carried out on patients with chronic simple glaucoma, some of whom had visual field defects in both eyes and some in one eye only. Some cases of ocular hypertension were included in this study, because it was highly probable that among them would be a proportion of individuals with incipient chronic simple glaucoma.

\section{Patients and methods}

The patients tested were attending the Glaucoma Clinic of the Institute of Ophthalmology and Moorfields Eye Hospital for routine diagnosis and management. All had shown intraocular pressures of more

Correspondence to the Secretary, Glaucoma Unit, Moorfields Eye Hospital, City Road, London ECIV 2PD. than $21 \mathrm{mmHg}$ with open angles. Those classified as chronic simple glaucoma had typical glaucomatous visual field defects in one or both eyes; if both fields were full, the patient was regarded as having ocular hypertension. A small number of normal volunteers, mostly relatives and friends accompanying patients, were also tested.

In some patients the Farnsworth Munsell 100 hue test was conducted in the usual way, while in others a modified procedure was used as follows. A wheel 26 in $(66 \mathrm{~cm})$ in diameter was fixed to a pivot mounted on an inclined base so as to be capable of rotation through $360^{\circ}$ (Fig. 1). Around its perimeter the wheel carried 89 nylon pegs measuring $\frac{3}{4}$ in $(1.9 \mathrm{~cm})$ in height and shaped to take the standard Farnsworth test caps. Four reference caps were permanently fixed to the wheel corresponding to the first reference cap on each of the Farnsworth 100 hue boxes; they were placed between the pegs of caps nos. 85 and 1, 21 and 22, 42 and 43, and 63 and 64 respectively. The 85 caps were kept on pegs fixed to the base of a tray below the wheel. Illumination was provided by 2 daylight fluorescent tubes fixed on each side of the wheel and enclosed in a metal reflector so that the light was evenly projected on to the wheel and tray. The luminance was around 


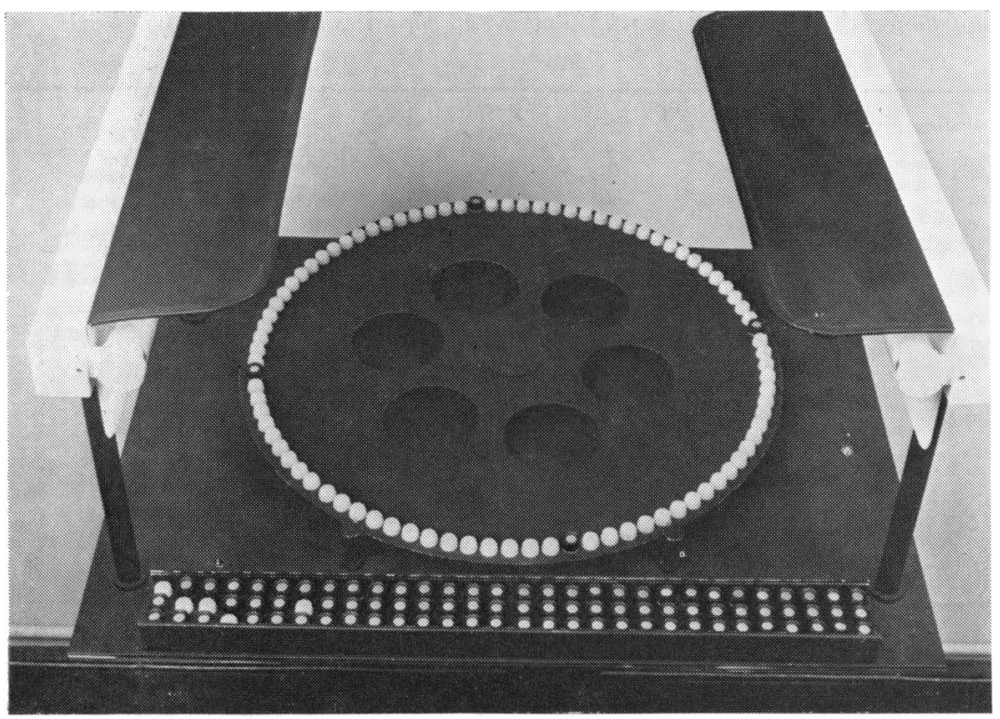

Fig. 1 Farnsworth-Munsell 100 hue colour vision test using the 'wheel' with nylon pegs mounted on an inclined base and fixed to a pivot and the Farnsworth-Munsell 100 hue caps kept on pegs fixed to a base illuminated by 2 daylight fluorescent tubes.

107 lux. The procedure was the same for the conventional Farnsworth-Munsell 100 hue test except that, instead of presenting the caps in 4 separate boxes, the caps were placed in a random fashion on the tray. The patient sat facing the wheel and was briefed with the details of the test. With one eye covered and wearing his near correction, if any, the patient was required to arrange the caps in the right order starting from the reference cap between peg 85 and 1 . When all caps had been fixed to the pegs on the wheel the positions of the caps were checked and marked on a special chart. The same procedure was repeated for the second eye.

A computer programme was developed to score and plot the results on a CIL model 7341 incremental plotter. The programme to produce the plots was written in Fortran and was run on an IBM $360 / 65$ computer. The raw data, that is the patient's response for each cap, were stored on magnetic discs having teen put there by means of a visual display unit connected to the computer. Before any scores were calculated or any plotting took place the data were checked by means of a programme which indicated any data points greater than 85 or appearing twice and which also pointed out any missing cap number. When the data were free from error, the plotting programme was run. This programme also calculated the score at each cap, the total score, and the average and percentage error for each box and for the four boxes combined, this information keing given in a table above the graph. The plot was obtained by converting the scores into $(x, y)$ co-ordinates and joining adjacent points. If the score at a particular cap was greater than 16 , it was not plotted in the normal way, since it would have meant drawing lines outside the chart. Instead, the score was written on the periphery of the chart and no lines were drawn to the adjacent points. The plot of the graph and table took about 10 minutes.

Paired $t$ tests comparing the mean difference in the scores of the standard 100 hue test and the 'wheel method' were carried out, and it was concluded that there was no systematic change in the scores with the wheel as compared with the standard test.

Cup:disc ratios were obtained from measurements of optic disc photographs as previously described. ${ }^{6} 7$

The visual fields were examined on a Goldmann perimeter by static presentation of the $\mathrm{I}: 4$ stimulus in 188 different positions within the central $25^{\circ} .8$ The extent of field loss was expressed as the number of stimuli not seen.

\section{Results}

ERROR SCORES

Table 1 summarises the average error scores for the 100 hue tests for normal subjects, glaucoma patients, and patients with ocular hypertension. The groups were matched for age and sex, and each group comprises results for 26 eyes. The average age throughout was 57 years. The glaucoma patients in Table 1 were 'unilateral' cases as regards field defects; that is to say, an intraocular pressure above $21 \mathrm{mmHg}$ had been found with open angles in both eyes, but in only one eye had a typical glaucomatous 
Table 1 Average error scores for normal subjects and for patients with 'unilateral' chronic simple glaucoma and ocular hypertension

\begin{tabular}{|c|c|c|c|c|c|c|}
\hline & \multirow{2}{*}{$\begin{array}{l}\text { Average } \\
\text { age } \\
\text { (years) }\end{array}$} & \multicolumn{5}{|c|}{ Average error scores } \\
\hline & & $\begin{array}{l}\text { Box } 1 \\
\text { Red to } \\
\text { yellow }\end{array}$ & $\begin{array}{l}\text { Box } 2 \\
\text { Yellow to } \\
\text { blue-green }\end{array}$ & $\begin{array}{l}\text { Box } 3 \\
\text { Blue-green } \\
\text { to blue }\end{array}$ & $\begin{array}{l}\text { Box } 4 \\
\text { Blue through } \\
\text { purple to red }\end{array}$ & Total \\
\hline Normal subjects & $57 \cdot 4$ & & & & & \\
\hline 26 eyes & & $13 \cdot 7$ & $16 \cdot 1$ & $16 \cdot 7$ & $17 \cdot 1$ & $63 \cdot 7$ \\
\hline Glaucoma patents & $57 \cdot 1$ & & & & & \\
\hline 26 eyes with field defects & & $37 \cdot 2$ & $49 \cdot 5$ & $50 \cdot 3$ & $43 \cdot 8$ & $180 \cdot 7$ \\
\hline 26 eyes with full fields & & $16 \cdot 8$ & $20 \cdot 3$ & $19 \cdot 0$ & $20 \cdot 8$ & 76.9 \\
\hline Ocular hypertension & $57 \cdot 0$ & & & & & \\
\hline 26 eyes & & $15 \cdot 0$ & $23 \cdot 6$ & $22 \cdot 7$ & $20 \cdot 1$ & $81 \cdot 3$ \\
\hline
\end{tabular}

Table 2 Interocular differences in error scores on 100 hue test

\begin{tabular}{|c|c|c|c|c|c|c|}
\hline & \multirow[b]{2}{*}{$\begin{array}{l}\text { No. of } \\
\text { individuals }\end{array}$} & \multicolumn{5}{|c|}{ Mean differences in error scores } \\
\hline & & $\begin{array}{l}\text { Box } 1 \\
\text { Red to } \\
\text { yellow }\end{array}$ & $\begin{array}{l}\text { Box } 2 \\
\text { Yellow to } \\
\text { blue-green }\end{array}$ & $\begin{array}{l}\text { Box } 3 \\
\text { Blue-green } \\
\text { to blue }\end{array}$ & $\begin{array}{l}\text { Box } 4 \\
\text { Blue through } \\
\text { purple to red }\end{array}$ & Total \\
\hline Normal subjects & 24 & $4 \cdot 2$ & 4.8 & $8 \cdot 8$ & $8 \cdot 3$ & $20 \cdot 0$ \\
\hline $\begin{array}{l}\text { Glaucoma patients with field defects } \\
\text { in both eyes }\end{array}$ & 16 & $24 \cdot 5$ & $22 \cdot 8$ & $29 \cdot 7$ & $33 \cdot 1$ & 96.9 \\
\hline Patients with ocular hypertension & 30 & $14 \cdot 3$ & $14 \cdot 2$ & $18 \cdot 8$ & $12 \cdot 8$ & $45 \cdot 6$ \\
\hline
\end{tabular}

field defect been demonstrated on the Goldmann perimeter. The details of the optic discs, visual fields, and Farnsworth-Munsell 100 hue tests of a typical patient from this group are shown in Figs. $2 \mathrm{a}, \mathrm{b}, \mathrm{c}$, and $3 \mathrm{a}, \mathrm{b}, \mathrm{c}$.

Table 2 gives the mean differences in scores between the 2 eyes of normal subjects, patients with 'bilateral' chronic simple glaucoma (i.e., with field defects in both eyes-a completely separate group from those in Table 1) and patients with ocular hypertension. The normal subjects and patients with ocular hypertension included those in Table 1.

The error scores were analysed statistically from 3 aspects: (a) comparison between the 4 boxes of the 100 hue test; $(b)$ comparison between the various groups of patients and subjects; (c) using differences in scores between the 2 eyes.

(a) Statistical analysis showed some significant differences between the scores for the various boxes, but there was no consistent pattern when the scores for all groups of eyes were considered.

(b) When the error scores for the various groups of eyes were considered, it was clear that the scores for eyes with glaucomatous field defects were higher than those for eyes in the other 3 groups $(P<0.001)$, and this was so for all 4 boxes and for total scores. Otherwise no differences at the 5\% level or less were found between the various groups of eyes.

(c) When differences in error scores between the 2 eyes of individual patients were analysed, those with bilateral glaucomatous field defects had significantly higher scores than normal subjects $(P<\mathbf{0 . 0 1})$. The glaucoma patients also differed from those with ocular hypertension except in the third box (bluegreen to blue). Patients with ocular hypertension were significantly different from normal subjects only in the first and second boxes (red to yellow and yellow to blue-green).

\section{CORRELATIONS BETWEEN 100 HUE ERROR SCORES AND CUP:DISC RATIOS}

Correlation between error score and amount of visual field loss. For the 26 glaucomatous eyes with field defects in Table 1 a highly significant correlation was found between the error score and the number of stimuli not seen in the visual field test $(r=0.61$, $\mathbf{P}<0.001)$. There was no correlation between the 


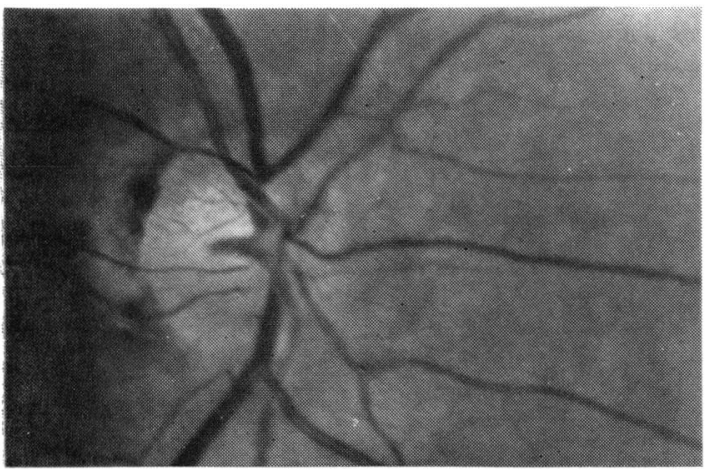

$2 a$

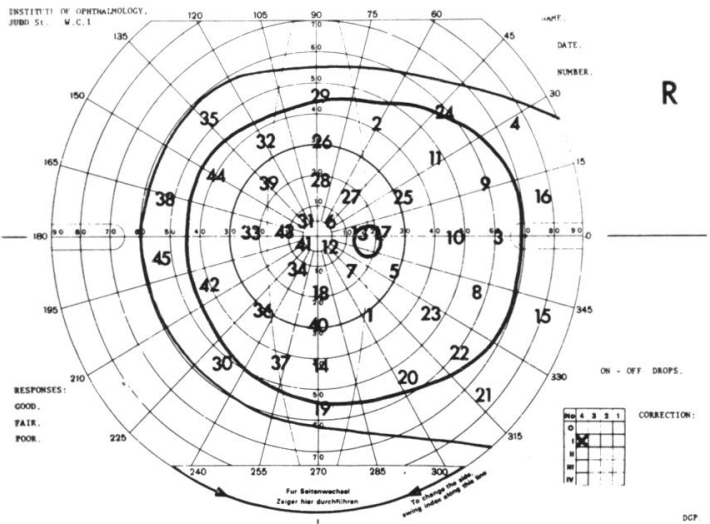

$2 b$

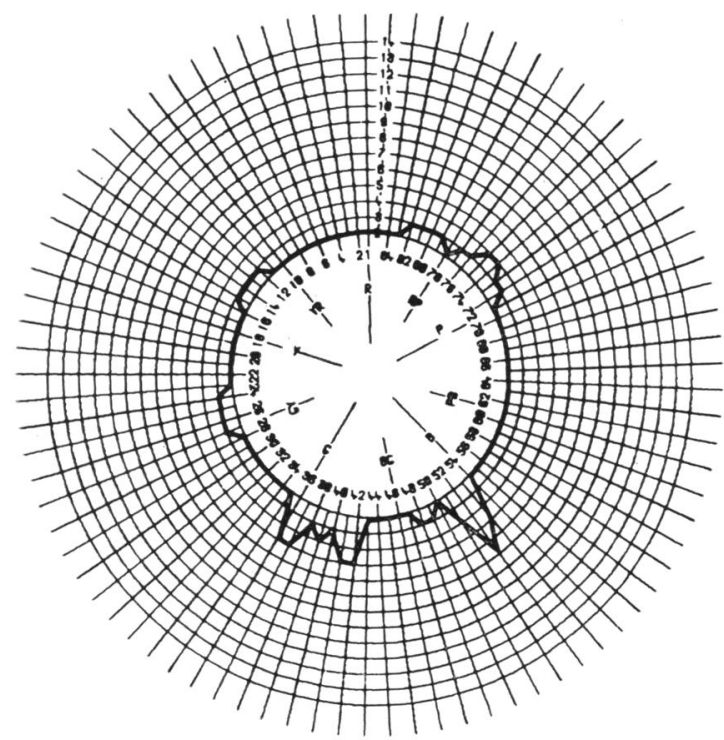

2c

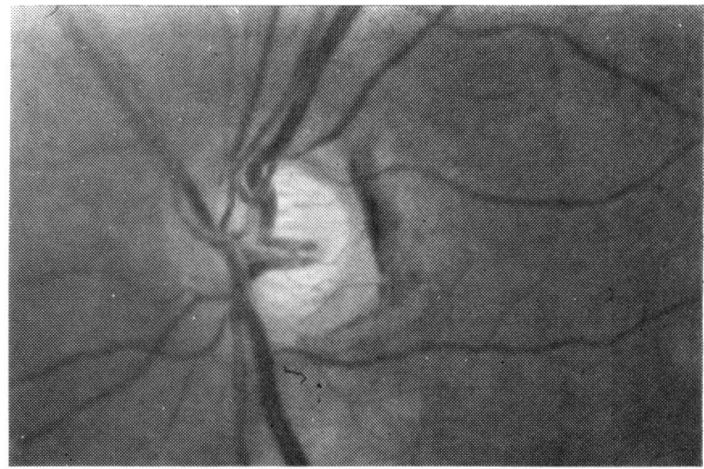

$3 a$

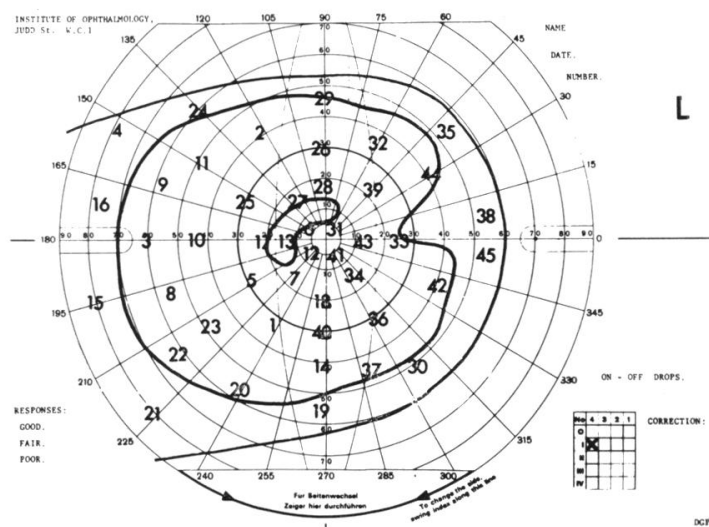

$3 b$

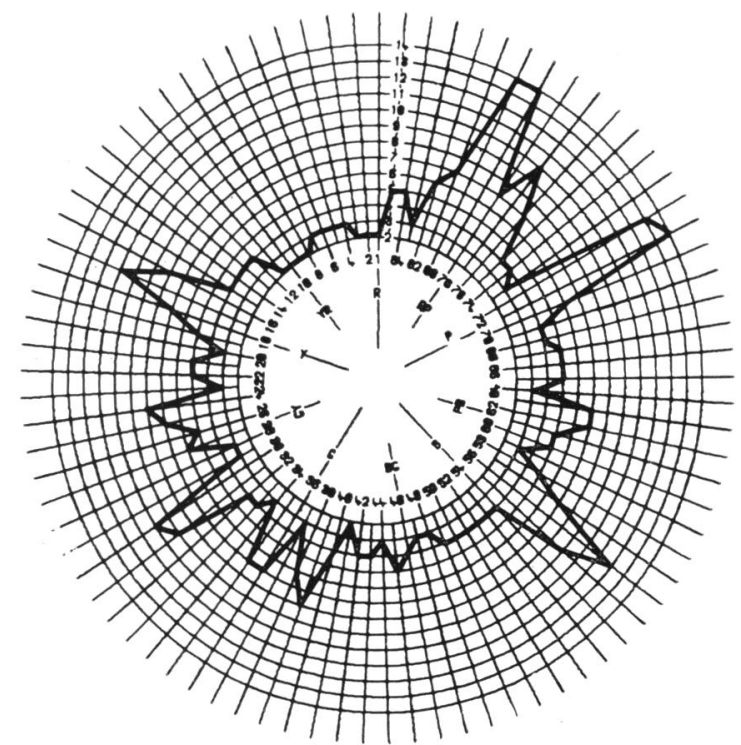

$3 c$

Figs. 2a, b, c (right eye) and 3a, b, c (left eye) Details of the optic discs (cup:disc ratio-right eye 0.55 and left eye 0.8 ), visual fields and Farnsworth-Munsell 100 hue colour vision tests of a 57-year-old male patient with chronic simple glaucoma, showing unilateral field defect (corrected visual acuity right eye 6/5 and left eye 6/4-pupils 4 mm right and left eyes). 
Table 3 Correlations between cup:disc ratios and 100 hue error scores in 'unilateral' chronic simple glaucoma

\begin{tabular}{llllll}
\hline Eye & $\begin{array}{l}\text { Box 1 } \\
\text { Red to } \\
\text { yellow }\end{array}$ & $\begin{array}{l}\text { Box 2 } \\
\text { Yellow to } \\
\text { blue-green }\end{array}$ & $\begin{array}{l}\text { Box 3 } \\
\text { Blue-green } \\
\text { to blue }\end{array}$ & $\begin{array}{l}\text { Box 4 } \\
\text { Blue through } \\
\text { purple to red }\end{array}$ & Total \\
\hline Right & $* * *$ & 0 & $* * *$ & 0 & $* *$ \\
Left & 0 & $* *$ & $* *$ & $* *$ & $* * *$ \\
Right minus left & $* * *$ & $* * * * *$ & 0 & 0 \\
Eyes with full fields & 0 & 0 & 0 & $* *$ & $*$
\end{tabular}

$0=$ No significant correlation. ${ }^{*} 0.05>P>0.01 . * * 0.01>P>0.001 . * * * 0.001>P$.

error score and the closeness of the field defect to fixation.

Correlation between error score and cup:disc ratio. The following correlations were computed: (1) between the right cup:disc ratio (CDR) and the right score; (2) between the left CDR and the left score; (3) between (right CDR minus left CDR) and (right score minus left score); (4) between CDR in eye with full field and score in eye with full field; (5) between CDR in eye with field defect and score in eye with field defect; (6) between (CDR in eye with field defect minus CDR in eye with full field) and (score in eye with field defect minus score in eye with full field).

These findings are summarised in Table 3, from which it can be seen that, when eyes with field defects were involved, some degree of correlation between CDR and score could be demonstrated, at varying levels of significance and usually not for the complete range of hues. Interocular differences in CDR and score gave the more significant correlations. In eyes with full fields no significant correlations between CDR and score were found.

In 24 patients with ocular hypertension a significant $(P<0.01)$ correlation was found between the interocular differences in CDR and the interocular differences in 100 hue score.

\section{Discussion}

The results show clearly that hue discrimination is well below normal in eyes with established chronic simple glaucoma, that is, when field defects are present. The finding of error scores above normal in eyes with full fields in glaucomatous patients and in cases of ocular hypertension suggests that impairment of hue discrimination occurs in the relatively early stages of the disease. The highly significant correlation between error score and the amount of visual field loss already reported by Austin ${ }^{9}$ shows that in the later stages of the disease reductions in hue discrimination and field deterioration take place together.

In glaucoma patients with field defects in both eyes the difference in error scores between the 2 eyes was greater than in normal subjects. This would appear to be a reflection of the difference in severity of glaucomatous damage frequently evident between the 2 eyes of individual patients. A similar result was obtained, though of smaller magnitude and limited to the first 2 boxes of the 100 hue test, in patients with ocular hypertension, suggesting that this group contained cases of incipient glaucoma.

The cup: disc ratio, measured from photographs of the optic disc, was used to provide an objective index of the stage of the disease. In glaucomatous patients with field defects in one eye only, the highly significant correlation which was found between the interocular differences of error score in the 100 hue test, and the interocular difference in cup:disc ratio strongly suggests that the degree of impairment of colour discrimination is related to the severity of glaucomatous damage to the optic discs. When the error scores and cup:disc ratios were analysed for the eyes with field defects, significant correlations between these parameters were again found, though not for the complete range of the 100 hue test; this finding also indicates that loss of colour discrimination is related to optic disc damage.

The finding of a correlation between cup:disc ratio and error score provides the possibility of extending the investigation to the stage of glaucoma in which a field defect has not been demonstrated. For example, the study can be extended to eyes with full fields in patients having established chronic simple glaucoma in the other eye, and to patients with ocular hypertension, some of whom can be presumed to be cases of incipient glaucoma. In the present investigation the results for these 2 groups, while not in disagreement, are not mutually supportive. No correlation was found between the magnitude of the cup:disc ratio and error scores in 
eyes with full fields in 'unilateral' chronic simple glaucoma. On the other hand interocular differences in cup:disc ratios showed a significant correlation with interocular differences in error scores in 24 patients with ocular hypertension. In this respect, it should perhaps be remembered that in glaucoma patients the most significant correlations between cup:disc ratios and error scores were found when interocular differences were analysed (Table 3). From the clinical viewpoint the suspicion that a patient with 'ocular hypertension' should be regarded as having early chronic simple glaucoma would seem to be increased by finding an asymmetry of hue discrimination which matched asymmetries of cup:disc ratio and intraocular pressure.

We wish to thank Mr L. Yerlett for constructing the wheel system, Mr H. Donovan for developing the computer program, the Audio Visual Department, Institute of Ophthalmology for illustrations, and Mrs J. Kennedy for typing the manuscript.

\section{References}

1 François J, Verriest G. Les dyschromatopsies acquises dans le glaucome primaire. Ann Oculistique 1959; 192: 191-9.

2 Zimmerman MM. Farbsinstorungen bei Glaukom. Klin Monatsbl Augenheilkd 1966; 148: 845-50.

3 Lakowski R, Bryett J, Drance S. A study of colour vision in ocular hypertension. Can J Ophthalmol 1972; 7: 86-95.

4 Fishman GA, Krill AE, Fishman M. Acquired colour defects in patients with open-angle glaucoma and ocular hypertension. Mod Probl Ophthalmol 1974; 13: 335-8.

5 Kalmus H, Luke J, Svedburgh D. Impairment of colour vision in pa.ients with ocular hypertension and glaucoma. Br J Ophthalmol 1974; 58: 922-6.

6 Gloster J, Parry DG. Use of photographs for measuring cupping in the optic disc. Br J Ophthalmol 1974; 58: 85062.

7 Gloster J. Vertical ovalness of glaucomatous cupping. Br J Ophthalmol 1975; 59: 721-4.

8 Gloster J. Flash perimetry. $B r J$ Ophthalmol 1970; 54: 649-58.

9 Austin DJ. Acquired colour vision defects in patients suffering from chronic simple glaucoma. Trans Ophthalmol Soc UK 1974; 94: 880-3. 